\title{
Phacoemulsification of Cataract in Patients Undergone Anterior Radial Keratotomy
}

DOI: 10.17691/stm2016.8.2.09

Received September 21, 2015

N.V. Pasikova, PhD Student,

A.A. Bikbulatova, MD, DSC, Ophthalmic Surgeon, $1^{\text {st }}$ Microsurgery Department;

M.M. Bikbov, MD, DSc, Professor, Director

Ufa Scientific Research Institute of Eye Diseases, Academy of Sciences of the Republic of Bashkortostan, 90. Pushkin St., Ufa, the Republic of Bashkortostan, 450008, Russian Federation

The aim of the investigation was to specify the conditions of performing cataract phacoemulsification in patients with previous anterior radial keratotomy (ARK), enabling optimization of the operation results.

Materials and Methods. We examined 27 patients (46 eyes) at the age of 44-62 years suffering age-related cataract of various density, who underwent ARK for myopia and myopic astigmatism $22.8 \pm 1.4$ years ago. Before the operation the refracting power of the cornea and axial eye length were determined. Intraocular lens power was calculated with the help of Hoffer $Q$ formula with corrections. All patients underwent cataract phacoemulsification with implantation of foldable intraocular lenses in the capsular bag through the tunnelshaped corneal or scleral access $2.2 \mathrm{~mm}$ wide.

Results. All operations were uneventful. Visual acuity without correction increased from $0.18 \pm 0.07$ to $0.54 \pm 0.07(p<0.05)$ on average, with correction from $0.29 \pm 0.04$ to $0.89 \pm 0.04$ ( $p<0.05$ ). Clinical refraction reached $-1.35 \pm 0.37 \mathrm{D}$ on average. Endothelial cell loss was $5.3 \%$ and did not exceed it in uncomplicated phacoemulsification. Creation of a "safety zone" in the form of intact cornea between the tunnel margins and keratomic scars not less than $0.5 \mathrm{~mm}$ wide prevented the risk of scar dehiscence during separate steps of phacoemulsification.

Conclusion. Precise determination of refracting corneal power and axial eye length, application of the third-generation Hoffer $Q$ formula with corrections, individual approach to the operation access selection depending on the width of the "safety zone" between the tunnel margins and keratomic scars, measures taken to protect endothelium during the operation allow the achievement of high functional results after cataract phacoemulsification in patients undergone ARK.

Key words: anterior radial keratotomy; cataract; cataract phacoemulsification.

Recently there has been observed a steady increase of appealability of patients, who underwent anterior radial keratotomy (ARK) in 80-s years of the last century for myopia and myopic astigmatism due to the development of age-related cataract. Phacoemulsification (PE) in this cohort requires individual approach because of the altered refracting power of the operated cornea, its mechanical weakness, reduction of endothelial cell density.

While performing phacoemulsification the following things should be kept in mind. The previous refractive intervention causes errors in the results of keratometry, as standard keratometers overrate the refracting power of the operated cornea [1-6]. Higher keratometric values may be obtained because a zone with greater refracting power falls into the measured area, while a more plane central corneal zone falls out of the metering. Application of ultrasound contact biometer for determining the axial length of the myopic eye with extensive staphyloma not coinciding with the macular zone, may also give higher values [7]. Standard methods of calculation of intraocular lens power without correction coefficients, taking into account the previous keratorefracting intervention may result in implantation of a weaker lens $[6,8,9]$. All the above listed factors cause refraction errors in postoperative period.

Histologically keratomic scars are characterized by a feebly marked cellular fibrous matrix and absence of proteoglycans. In the scars there are defects of Bowman's membrane, into which the epithelium grows forming an epithelial plug [10]. Such structure leads to weakening of the cornea strength properties and causes dehiscence of keratotomic scars in traumas and surgical interventions [11-14]. Scar marginal diastasis during cataract PE may occur when a tunnel-shaped incision crosses the keratotomic scar or is made in its close vicinity. It may lead to the increase of cornea tunnel dimension, of tunnel malformation, and as a consequence to the excessive issue of the irrigation solution through the tunnel. The arising instability of the anterior chamber may cause damage of corneal posterior epithelium, iris, posterior lens capsule. Difficulty of corneal incision hydration demands suturing of the tunnel or deconditioned corneal keratotomic scar [13].

For contacts: Natalia V. Pasikova, email: natiracool@mail.ru 
Though ARK is referred to the operations of a nonpenetrating type, some authors link the decrease of corneal epithelial cell density after keratotomy with the availability of intraoperative micro- and macroperforations, with a large number of incisions, a small diameter of the central optical zone, duration of the postoperative inflammation reaction $[15,16]$.

The facts presented show, that when working with patients having age-related cataract after ARK, it is necessary to calculate correctly the optical power of the implanted intraocular lens in order to avoid refraction error in the postoperative period; to apply maximally sparing manipulations during the operation to prevent dehiscence of the keratotomic scars and damage of the corneal endothelial cells.

The aim of the investigation was to specify the conditions of performing cataract phacoemulsification in patients with previous anterior radial keratotomy, enabling optimization of the operation results.

Materials and Methods. 27 patients (46 eyes) at the age of $44-62$ years (the average age $52.4 \pm 3.7$ years) with age-related cataract undergone previously ARK have been examined. The number of keratotomic scars varied from 6 to 18 (6 scars in 8 eyes, 8 in 10 eyes, 10 in 7 eyes, 12 in 8 eyes, 14 in 5 eyes, 16 in 5 eyes, 18 in 3 eyes). $22.8 \pm 1.4$ years on average passed from the time of ARK performance.

The study complies with the Declaration of Helsinki (the Declaration was passed in Helsinki, Finland, June, 1964, and revised in October, 2000, Edinburg, Scotland) and was performed following approval by the local ethic committee. Written informed consent was obtained from every patient.

All patients underwent a standard complex of ophthalmological examination: visual acuity, refractometry, keratometry, tonometry, perimetry, keratotopography, endothelial microscopy, biometry, biomicroscopy, ophthalmoscopy.

Visual acuity without correction was $0.18 \pm 0.07$ on average, with correction $0.29 \pm 0.04$. The eyes were distributed according to the degree of cataract density (Buratto classification) as follows: grade $2-18$ eyes (39\%), grade $3-25$ eyes $(54 \%)$, grade $4-3$ eyes $(7 \%)$. Endothelial cell density

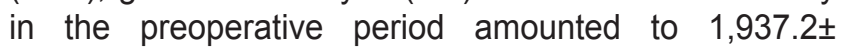
$402.6 \mathrm{cells} / \mathrm{mm}^{2}$ (Figure 1).

Refracting power of the corneal anterior surface was measured with the help of TMS-4 automatic corneal keratotopographer (Tomey, Japan). Axial eye length was determined using contact-free laser IOL Master interferometer (Carl Zeiss, Germany) and contact ultrasound Ocuscan biometer (Alcon, USA). The length of anterior-posterior eye axis was measured ten times at a minimal probe pressure on the cornea.
Intraocular lens power was calculated according to the third-generation Hoffer $Q$ formula taking into account TMS-4 keratotopographer data, selecting the least values of the corneal refracting power in two main meridians in $3.0 \mathrm{~mm}$ zone [8]. The choice of Hoffer $\mathrm{Q}$ formula was determined by our previous positive experience of using it for patients after ARK, when the calculated refraction was the nearest to the actual one obtained after PE [17]. Correction was made by adding 2.5-3.0 D to the optical power of the calculated lens in order to achieve a weak myopic refraction within the range of -1.0 to $-2.0 \mathrm{D}$ in the postoperative period.

Cataract PE with implantation of foldable intraocular lenses in the capsular bag through a tunnel corneal or sclera access $2.2 \mathrm{~mm}$ wide was performed by one and the same surgeon. Taking into consideration our previous experience of PE in patients after ARK, when keratotomic scar margins happened to separate in four eyes (in the tunnel zone during the work by the phaco handpiece (Figure 2) in 1 eye; in the tunnel zone during intraocular lens implantation (Figure 3 ) - in 3 eyes), we defined the "safety zone" in the form of intact cornea

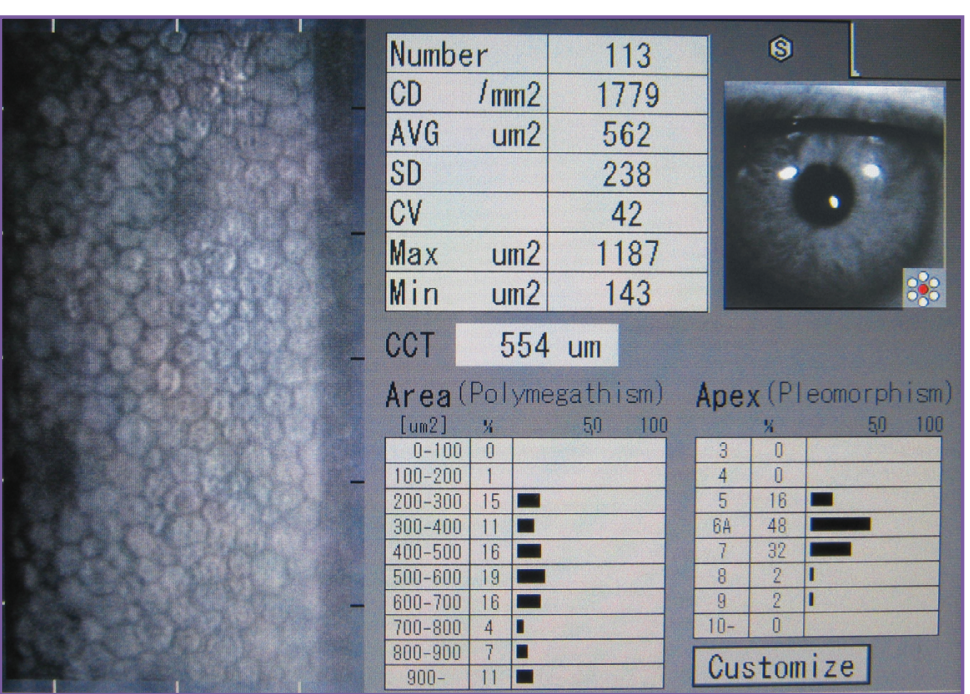

Figure 1. Endothelial microscopy of the patient's cornea after anterior radial keratotomy with cataract

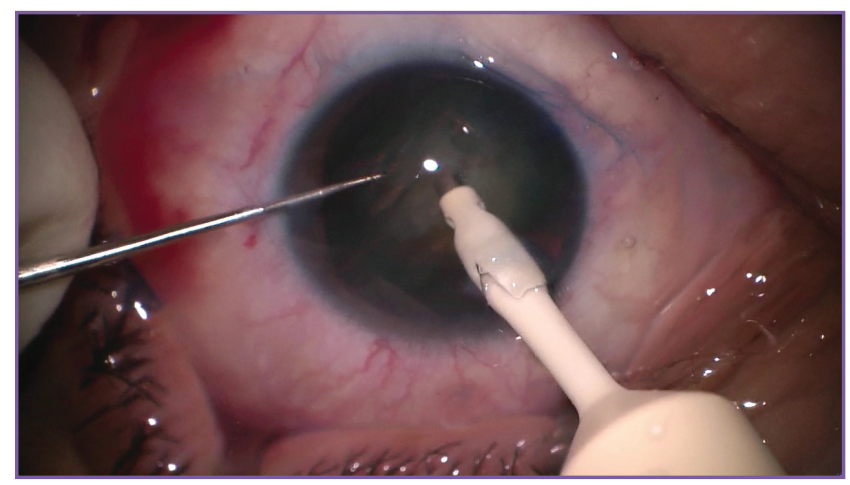

Figure 2. Dehiscence of keratotomic scar margins during the work with a phaco handpiece 


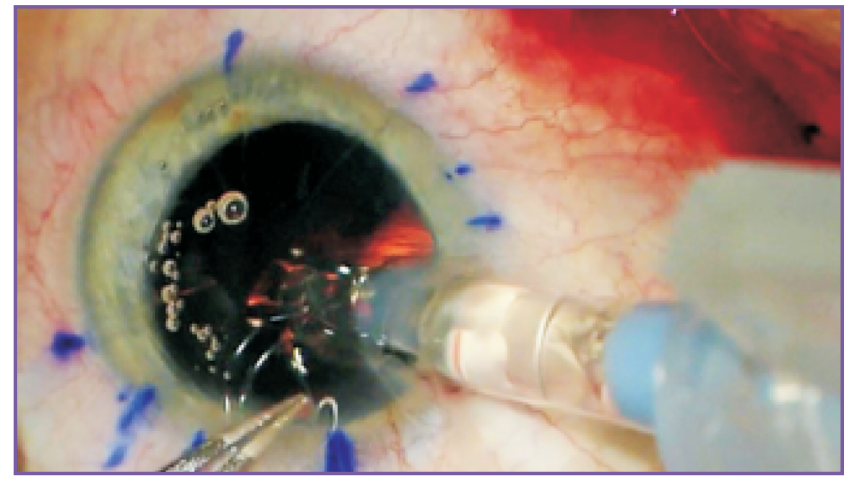

Figure 3. Dehiscence of keratotomic scar margins during intraocular lens implantation

between the margins of the tunnel and keratotomic scars with the help of the original measuring instrument [18]. The recommended width of the "safety zone" for corneal access is not less than $0.5 \mathrm{~mm}$; if the value was less than $0.5 \mathrm{~mm}$, preference was given to the scleral access.

Considering initial low density of the corneal endothelial cells after ARK we used low energy modes of ultrasound (pulse, torsion, burst), and cohesive viscoelastics; all manipulations with the nucleus and lens masses we tried to perform within the limits of the capsular bag.

The height of the bottle with the irrigation solution was as minimal as possible in order to decrease the quantity and velocity of the liquid going through the anterior chamber.

SeeLens AF (Hanita, Israel) intraocular lenses were implanted in 29 eyes (63\%), and Centerflex (Rayner, England) lenses were implanted in 17 eyes (37\%). The stabilized refraction obtained was assessed 12 months after the operation.

Results and Discussion. There were no complications during the operations, postoperative period was also uneventful. Uncorrected visual acuity amounted to $0.54 \pm 0.07$ on average 1 year after the operation, while the corrected acuity was $0.89 \pm 0.04$. Clinical refraction reached $-1.35 \pm 0.37 \mathrm{D}$. Myopia in the range of $-0.75 \ldots-1.0 \mathrm{D}$ was noted in 14 eyes (30\%), and in 32 eyes myopic refraction amounted to $-1.25 \ldots-2.0 \mathrm{D}$.

Measurement of the corneal refracting power in patients after ARK with the help of modern scanning keratotopographers, axial eye length using noncontact laser interferometers, as well as application of the thirdgeneration formula with corrections for calculation of intraocular lens power allowed us to avoid hyperopic refraction in the postoperative period. Weak myopia gave the patients subjective satisfaction with near visual acuity without correction and preserved sufficient uncorrected distance visual acuity.

The density of corneal endothelial cells was $1,834.8 \pm 391.3$ cells $/ \mathrm{mm}^{2}$ on average, i.e. the loss amounted to $5.3 \%$ and did not exceed it in uncomplicated PE due to the complex measures taken to protect endothelium. Creation of the "safety zone" in the form of the intact cornea between the margins of the tunnel and keratotomic scars not less than $0.5 \mathrm{~mm}$ wide prevented the risk of scar dehiscence during separate stages of PE.

Conclusion. Precise determination of refracting corneal power and axial eye length, application of the third-generation Hoffer $Q$ formula with corrections, individual approach to the operation access selection depending on the width of the "safety zone" between the tunnel margins and keratotomic scars, measures taken to protect endothelium during the operation allow the achievement of high functional results after cataract phacoemulsification in patients after ARK.

Study Funding and Conflicts of Interest. The work was not supported by any sources, and there is no conflicts of interest related to this study.

\section{References}

1. Avetisov S.E., Mamikonyan V.R., Kas'yanov A.A. Calculation of IOL optical power in patients with radial keratotomy in the medical history. Oftal'mologiya 2004; 1(4): 15-24.

2. Neroev V.V., Tarutta E.P., Khodzhabekyan N.V., Khandzhyan A.T., Penkina A.V., Milash S.V. Using Galilei G2 scheimpflug analyser to determine anatomical and optical parameters of the cornea after refractive corneal surgery. Rossiyskiy oftal'mologicheskiy zhurnal 2014; 2: 5-9.

3. lusef lu.N., Kas'ianov A.A., Ivanov M.N., lusef S.N., Vvedenskii A.S., Ryzhkova E.G., Shevelev A.lu. Calculation of intraocular lens power in non-standard clinical situations. Vestnik oftal'mologii 2013; 129(5): 62-66.

4. Geggel H.S. Intraocular lens power selection after radial keratotomy. Ophthalmology 2015; 122(5): 897-902, http:// dx.doi.org/10.1016/j.ophtha.2014.12.002.

5. Gusev Yu.A., Belikova E.I., Tret'yak E.B., Zhezheleva L.V. Intraocular lens power calculation after radial keratotomy (clinical case). Kataraktal'naya $i$ refraktsionnaya khirurgiya 2015; 15(2): 41-46.

6. Lyle W.A., Jin G.J. Intraocular lens power prediction in patients who undergo cataract surgery following previous radial keratotomy. Arch Ophthalmol 1997; 115(4): 457-461, http://dx.doi.org/10.1001/archopht.1997.01100150459001.

7. Rajan M.S., Keilhorn I., Bell J.A. Partial coherence laser interferometry vs conventional ultrasound biometry in intraocular lens power calculations. Eye 2002; 16(5): 552-556, http://doi.org/10.1038/sj.eye.6700157.

8. Stakheev A.A., Balashevich L.I. A new method of calculating intraocular lens power for patients with cataract undergone previously radial keratotomy. Oftal'mokhirurgiya 2008; 2: 26-33.

9. Seitz B., Langenbucher A. Intraocular lens power calculation in eyes after corneal refractive surgery. $J$ Refract Surg 2000; 16(3): 349-361.

10. Khoroshilova-Maslova I.P., Andreeva V.P., Ilatovskaya L.V., Kuznetsova I.A. Clinical and histopathological investigation of enucleated eyes with contusion corneal rupture after radial keratotomy. Vestnik oftal'mologii 1998; 114(4): 3-8.

11. Volkov V.V., Dal' G.A., Tulina V.M., Kulikov B.C., 
Gavrilova N.K., Nikolaenko V.P. Contusion ruptures of the eye capsule along the postoperative corneal-limbal scars. Vestnik oftal'mologii 1998; 114(2): 17-20.

12. Baudot A., Perone J.M., Agapie A., Lacusteanu M., Lasota P., Kurun S., Mnasri H., Bertaux P.J. Rupture of two radial keratotomy incisions 19 years later, during a clear corneal cataract surgery. Investigative Ophthalmology \& Visual Science 2011; 52(14): 6221.

13. Behl S., Kothari K. Rupture of a radial keratotomy incision after 11 years during clear corneal phacoemulsification. J Cataract Refract Surg 2001; 27(7): 1132-1134, http://dx.doi. org/10.1016/S0886-3350(01)00763-5.

14. McNeill J.I. Corneal incision dehiscence during penetrating keratoplasty nine years after radial keratotomy. J Cataract Refract Surg 1993; 19(4): 542-543, http://dx.doi. org/10.1016/S0886-3350(13)80620-7.

15. Mac Rae S.M., Matsuda M., Rich L.F. The effect of radial keratotomy on the corneal endothelium. Am J Ophthalmol 1985; 100(4): 538-542, http://dx.doi.org/10.1016/00029394(85)90677-4.

16. Frueh B.E., Böhnke M. Endothelial changes following refractive surgery. J Cataract Refract Surg 1996; 22(4): 490496, http://dx.doi.org/10.1016/S0886-3350(96)80048-4.

17. Surkova V.K., Shevchuk N.E., Pasikova N.V. Izmeritel'nyy instrument dlya rascheta parametrov khirurgicheskogo dostupa pri fakoemul'sifikatsii katarakty $u$ patsientov posle radial'noy keratotomii [A measuring tool for calculation of surgical access paramertes in phacoemulcification of cataract in patients after radial keratotomy]. Patent RU 2552096. 2014.

18. Bikbov M.M., Bikbulatova A.A., Pasikova N.V. Retrospective analysis of the accuracy of IOL power calculation formulas after anterior radial keratotomy. Kataraktal'naya $i$ refraktsionnaya khirurgiya 2015; 15(4): 26-29. 